This is not explained by the process of data collection as care has been taken to make the data from both sources comparable. To determine the reasons for this marked difference in outcome more extensive investigation is required.

We thank Debbie Sen, Dr Judith Rankin, and Marjorie Renwick of the Regional Maternity Survey Office, Newcastle upon Tyne for their help in compiling the Northern region data and Vicki Ashton of Teesside University for statistical advice.

Contributors: GH had the original idea for the study and coordinated the data analysis. LMI supplied the data from Norway. RTL supplied the statistical expertise. The paper was written jointly by GH, LMI, and RTL.

Conflict of interest: None.
1 Hawthorne G, Robson S, Ryall EA, Sen D, Roberts SH, Ward Platt MP Prospective population based survey of outcome of pregnancy in diabetic women: results of the Northern Diabetic Pregnancy Audit, 1994. BMJ 1997;315:279-81.

2 Casson IF, Clarke CA, Howard CV, McKendrick O, Pennycook S, Pharoah POD, et al. Outcomes of pregnancy in insulin dependent diabetic women: results of a five year cohort study. BMJ 1997;315:275-8.

3 Hadden DR, McCance D, Traub AI. Ten year outcome of diabetic pregnancy in Northern Ireland: the case for centralisation. Diabetic Med 1998(suppl 1);15:S16.

4 Hellesen HB, Vikane E, Lie RT, Irgens LM. Maternal diabetes: falling perinatal mortality but still high foetal growth. Tidsskr Nor Laegeforen 1996;116:3465-9.

5 Diabetes Care and Research in Europe: the Saint Vincent Declaration WHO/IDF Europe. Diabetic Med 1990;7:360.

\title{
Decrease in effectiveness of routine surveillance of Haemophilus influenzae disease after introduction of conjugate vaccine: comparison of routine reporting with active surveillance system
}

\author{
Babatunde Olowokure, Jeremy Hawker, Iain Blair, Nick Spencer
}

In October 1992 routine immunisation with Haemophilus influenzae type $\mathrm{b}$ conjugate vaccine was introduced in the United Kingdom, and the incidence of disease was subsequently reported to have decreased 15-fold. ${ }^{1}$ The surveillance systems in place were primarily routine and were known to underestimate the burden of invasive $H$ influenzae disease. ${ }^{2}$ This study aimed to determine whether underreporting continued after introduction of the conjugate vaccine, and how this might affect the reported success of the vaccine. Results of routine surveillance were compared with active surveillance for invasive $H$ influenzae disease in the West Midlands health region of England.

\section{Subjects, methods, and results}

Invasive H influenzae disease was defined as an illness in which the organism was isolated from a sterile site in children aged $<5$ years admitted to hospital in the West Midlands from October 1990 to September 1992 (pre-vaccine) and from October 1992 to September 1994 (post-vaccine).

Data from voluntary laboratory reports to the Public Health Laboratory Service Communicable Disease Surveillance Centre (routine system) were compared with a system that combined data from the Communicable Disease Surveillance Centre, statutory notifications, laboratory records, hospital paediatricians, and the British Paediatric Surveillance Unit study of conjugate vaccine failures (active system). Hospitals and laboratories were visited to validate reports and collect demographic data. Only children aged $<5$ years who lived in the West Midlands are included in the analysis.

Of 244 West Midlands cases identified, only 200 cases had been reported to the routine surveillance system (table). Significantly fewer cases were reported to the routine surveillance system than to the active surveillance system in the post-vaccine period than in the pre-vaccine period ( $\mathrm{P}=0.0018$, table). Overall, the proportion of children aged $<2$ years identified by the routine surveillance system was significantly lower than that of children aged $>2$ years $(\mathrm{P}=0.0065$, table). Reporting by ethnic group, sex, or mortality did not differ significantly. Of seven cases reported to the British Paediatric Surveillance Unit, only three were reported to the routine surveillance system. Incidence rates based on reports to the routine surveillance system for the pre-vaccine and post-vaccine periods were 23.4 per 100000 children $<5$ years old $(95 \%$ confidence interval 19.9 to 27.2 ) and 5.1 (3.6 to 7.1) respectively. This compares with 27.1 (23.3 to 31.2) and 7.7 (5.8 to 10.0) using active surveillance data. The table shows that effectiveness of routine surveillance decreased by $23 \%$ after introduction of the vaccine, with consequent overestimation of the effectiveness of the immunisation programme.

Comparison of cases of invasive Haemophilus influenzae disease in children $<5$ years identified by active surveillance and reports to the Communicable Disease Surveillance Centre (routine system) before and after introduction of the vaccine: West Midlands Health Region 1990-4

\begin{tabular}{lccc} 
& $\begin{array}{c}\text { Routine } \\
\text { surveillance } \\
\text { system }\end{array}$ & $\begin{array}{c}\text { Active } \\
\text { surveillance } \\
\text { system }\end{array}$ & $\begin{array}{c}\text { Proportion (95\% Cl) of } \\
\text { routine: active cases }\end{array}$ \\
\hline Total number of cases: & 200 & 244 & 81.9 (76.8 to 86.4) \\
\hline Oct 1990-Sept 1992 & 164 & 190 & 86.3 (80.9 to 90.7) \\
\hline Oct 1992-Sept 1994 & 36 & 54 & 66.7 (53.4 to 78.2) \\
\hline Cases of meningitis: & 136 & 165 & 82.4 (76.0 to 87.7) \\
\hline Oct 1990-Sept 1992 & 113 & 130 & 86.9 (80.3 to 91.9) \\
\hline Oct 1992-Sept 1994 & 23 & 35 & $65.7(49.0$ to 79.9$)$ \\
\hline Cases of non-meningitic invasive disease: & 64 & 79 & $81.0(71.2$ to 88.5$)$ \\
\hline Oct 1990-Sept 1992 & 51 & 60 & 85.0 (74.3 to 92.4) \\
\hline Oct 1992-Sept 1994 & 13 & 19 & 68.4 (45.5 to 86.1) \\
\hline Age group (months): & 139 & 179 & 77.7 (71.1 to 83.3) \\
\hline 0-23 & 61 & 65 & 93.8 (85.8 to 98.0) \\
\hline 24-59 & & &
\end{tabular}


Department of Public Health and Epidemiology,

University of

Birmingham,

Edgbaston,

Birmingham

B15 2TT

Jeremy Hawker

consultant

epidemiologist

Department of

Public Health,

Sandwell Health

Authority, West

Bromwich B70 9LD

Iain Blair

consultant in

communicable disease

control.

Correspondence to:

B Olowokure,

Public Health

Laboratory Service

Communicable

Disease

Surveillance Centre,

West Midlands,

Heartlands

Hospital,

Birmingham

B9 5SS

bolowokure@

cdscwmid.demon.

co.uk

\section{Comment}

The reliability of surveillance systems can affect the observed effectiveness of public health interventions. H influenzae meningitis is a life threatening disease and most cases occur before the age of 2 years. ${ }^{3}$ In this study cases of $H$ influenzae meningitis in this age group were those most likely to be missed. The publicity surrounding the launch of the vaccine and the national study of vaccine failures ${ }^{4}$ might have been expected to improve reporting efficiency. However, we found that the introduction of the vaccine was associated with significantly increased underreporting, perhaps because of factors such as complacency following the success of the vaccine in reducing the incidence of the disease or an assumption that reporting to the British Paediatric Surveillance Unit was sufficient. These findings are relevant as continuing surveillance is needed to assess the effectiveness of the programme, identify vaccine failures, and monitor changes in predominant strains of the organism. A meningococcal vaccine is being introduced into the immunisation schedule in the United Kingdom. ${ }^{5}$ To measure the impact of this and other new vaccines accurately, the quality of the data sources for communicable disease surveillance must be ensured.

We are grateful to the Public Health Laboratory Service Communicable Disease Surveillance Centre and all the consult- ant microbiologists, consultants in communicable disease control, immunisation coordinators, consultant paediatricians, and medical records managers who contributed to this study by providing information on their patients. We are also grateful to the Oxford Vaccine Group for providing information on cases reported to it as part of the British Paediatric Surveillance Unit study of Hib conjugate vaccine failures.

Contributors: BO and NS conceived the study. BO collected data in the field and was responsible for data management and for preparation of the manuscript. JH and IB participated in the execution of the study. All authors contributed to data analysis and interpretation and participated in manuscript revision and approval of the final version. BO and NS are guarantors for the study.

Funding: This study was funded by a grant from the charities of the City of Coventry and partly funded by the Warwickshire Child Health Group.

Competing interests: None.

1 Hargreaves RM, Slack MPE, Howard AJ, Anderson E, Ramsay ME. Changing patterns of invasive Haemophilus influenzae disease in England and Wales after introduction of the Hib vaccination programme. BMJ 1996;312:160-1.

2 Macleod CA. Haemophilus influenzae: the efficiency of reporting invasive disease in England and Wales. Commun Dis Rep CDR Rev 1994;4:R13-16.

3 Nazareth B, Slack MPE, Howard AJ, Waight PA, Begg NT. A survey of invasive Haemophilus influenzae infections. Commun Dis Rep CDR Rev 1992;2:R13-16.

4 Salisbury DM. The introduction of Haemophilus influenzae type b immunization into the United Kingdom: practical steps to assure success. Pediatr Infect Dis J 1998;17:S136-9.

5 Wise J. UK introduces new meningitis C vaccine. BMJ 1999;319:278.

(Accepted 15 May 2000)

\section{Reduced risk of hospital admission for childhood asthma among Scottish twins: record linkage study}

David P Strachan, Sarah E Moran, Kevin McInneny, Mary Smalls

Department of

Public Health

Sciences,

St George's

Hospital Medical

School, London

SW17 0RE

David P Strachan

professor of

epidemiology

Sarah E Moran

statistician

Information and Statistics Division,

National Health

Service in Scotland,

Trinity Park House,

Edinburgh

EH5 3SO

Kevin McInneny

programmer

Mary Smalls

head of statistics

Correspondence to:

D P Strachan

d.strachan@sghms.

ac.uk

BMJ 2000;321:732-3
A recent study of Swedish army conscripts found a reduced prevalence of asthma and allergic rhinitis among twins. ${ }^{1}$ We analysed routine data on hospital admissions in Scotland to compare risks of asthma and other respiratory complaints among twins and singletons.

\section{Subjects, methods, and results}

We identified all twins born in Scotland during 1981-4 from computerised maternity records. Subsequent admissions of twins to Scottish hospitals during 1981-94 were ascertained by probability matching on the basis of date of birth, sex, and surname. This matching is considered $99 \%$ accurate for singletons, but for twins it is reliable only at the level of the pair: which twin is admitted cannot be identified with certainty.

We identified hospital admissions for respiratory disease (ICD-9 (international classification of diseases, 9th revision) codes 464, 466, 480-486, and 490-496) for all Scottish children born during 1981-4. Rates of hospital admission among singletons and twins up to 10 years of age were compared by cause and sex, assuming Poisson errors in the numerators.

Twins were significantly less likely than singletons to be admitted for respiratory diseases (table). This was attributable to a reduced risk of admission for asthma among twins (code 493) by more than half throughout the age range $0-10$ years. In contrast, twins were at significantly increased risk of admission for acute bronchitis and bronchiolitis (code 466). Admissions for other respiratory diseases were divided more equally between twins and singletons (table).

No significant differences were found between twins of the same or different sex in admission rates for any cause or all respiratory diseases combined. The relative difference in rates of admission with asthma for twins of the same sex compared with singletons was greater for males than for females, although this sex interaction was not significant.

\section{Comment}

Our record linkage study confirms that twins are at reduced risk of asthma but not of other respiratory diseases than are singletons. The twofold difference in rates for admissions with asthma between Scottish twins and singletons is greater than the difference in asthma prevalence (4.9\% versus 5.9\%) reported among Swedish army conscripts. ${ }^{1}$ Cases admitted to hospital possibly represent more severely affected patients among whom the "twin effect" is more influential. 